qui, ayant publié un ouvrage d'ordre scientifique sur l'Afrique, postule et verse sa cotisation. L'Assemblée générale des membres du Cercle se réunira au moins une fois par an.

\title{
African Study Centre in the Netherlands
}

THE African Study Centre at the University of Leyden was originally a branch of the Afrika Instituut in Rotterdam, which was mainly concerned with economic and commercial questions. The centre at Leyden has now developed into a centre for linguistic and sociological studies, available to students of the University. Lecturerships in African Linguistics, Ethnology, and Sociology have been founded.

\section{Field Research in Liberia}

Mr. James L. Grbbs, Jr., is undertaking a field study of the customary law of the Kpelle tribe of Gbarnga District, Central Province, north of Monrovia. His research, which is sponsored by the Ford Foundation, New York, will be devoted particularly to a study of judicial procedure and the function of law as an instrument of social control.

\section{Catalogue of Publications in the Bantu Languages of Southern Africa}

The Conference on Christian Literature for the Bantu of Southern Africa, held in Johannesburg in August 1956, stressed the necessity of publishing a catalogue of all Christian publications available in the Bantu languages of Southern Africa. 'Informo' (Christian Literature Service, Secretary J. Semmelink) has undertaken to prepare such a catalogue, and a preliminary list based on information supplied by publishers, has been duplicated and circulated. It includes titles in Pedi, Sotho, Xhosa, Zulu, Tswana. When more or less complete lists for any one language have been compiled, periodic supplements will be issued, as well as separate lists of, for example, periodicals, linguistic publications, school-books, \&c.

\section{Light on Nigeria's History}

A reasonably certain date has now been arrived at for the Nok sculptures, ${ }^{\mathrm{I}}$ whose discovery in 'Middle Belt' areas of Northern Nigeria in recent yeats radically alters all conceptions of Nigerian history. It was always clear that the existence of such sophisticated work, probably at least 1,000 years old, in areas of Nigeria now considered 'backward', made nonsense of common notions of African history. But there has been some doubt about their date, and Mr. Bernard Fagg, who is chiefly responsible for their discovery, would never commit himself on it.

Now news has been received that the latest samples of semi-carbonized wood, found embedded in the middle of the main bed of grey-black clay, which marks the final phase of the Nok Figurine Culture, have been analysed for their radiocarbon content at Yale University and have proved to be 1,750 years old (with a probable margin of error of only so years each way), which makes the very end of the Nok Culture date from about A.D. 200.

Some semi-carbonized wood samples from the gravels below the clay where most of the figurines have been found, which were collected in I950 and finally analysed in December 1956, suggest that the Nok figurines probably date back at least to about 900 B.C. Such a date dispels the scepticism with which the tentative date for this sophisticated art of the Nok people, and for the introduction of metal-working, was previously received. It gives, too, the first relatively firm date for the prehistoric cultures of West Africa, from which studies can develop both forwards and backwards in time.

\footnotetext{
I See Africa, xv, 1945, pp. 21, 22.
} 